\title{
A DECISÃO COMO RESULTADO DE UM PROCESSO SOCIAL DA INFORMAÇÃO COMPARTILHADA
}

\section{LA DECISIÓN COMO RESULTADO DE UN PROCESO DE INFORMACIÓN COMPARTIDA}

\begin{abstract}
Mario Lúcio Caixeta - caimar@terra.com.br
Mestrando em Ciência da Informação pela Escola de Ciência da Informação da Universidade Federal de Minas gerais (ECI/UFMG). Professor substituto da Escola de Ciência da Informação da Universidade Federal de Minas gerais (ECI/UFMG).
\end{abstract}

Ricardo Barbosa Rodrigues - ricardobarbosa@ufmg.br

Doutor em Administração pela Columbia University. Pós-doutor pela Faculty of Information Studies da University of Toronto. Professor titular da Escola de Ciência da Informação da Universidade Federal de Minas Gerais (ECI/UFMG).

\begin{abstract}
Resumo
Decisões dependem da qualidade, confiabilidade e capacidade de interpretação das informações e das fontes utilizadas pelos gerentes. São atos na maioria das vezes solitários, que normalmente podem ser entendidos com base no princípio da racionalidade limitada. Os aspectos não racionais da decisão tendem a ser explicados pela experiência, talento e intuição de quem decide. Por sua vez, o decisor se encontra submetido às alternativas geradas através da sua rede de informação e se envolve em freqüentes decisões de inovação, fundamentais à sobrevivência de seus negócios. No cenário sociocultural de um arranjo produtivo local (APL), a prática do compartilhamento de informações com outros empresários locais, seus empregados, familiares e outras instituições parceiras, podem transformar tais decisões num produto coletivo e social, a partir do envolvimento desses atores na responsabilidade $e$ construção conjunta do processo. O presente
\end{abstract}

trabalho, baseado em um projeto de pesquisa de doutorado, tem como objetivo desenvolver um modelo de decisão que possa explicar o comportamento de uso da informação do gerente de uma pequena e média empresa, a partir de seu contexto sociocultural.

\section{Palavras-Chave: \\ Processo decisório; Pequenas e médias empresas; Ambiente informacional; Arranjos produtivos locais; Compartilhamento da informação.}




\section{INTRODUÇÃO}

O funcionamento das organizações, seja quando orientadas para o lucro ou para quaisquer outras atividades sociais, se fundamenta em decisões de vários tipos e níveis, as quais viabilizam seu funcionamento interno, desenvolvimento e adaptação às condições impostas pelo ambiente externo. Gerir a rotina e o futuro da instituição pode refletir, em grande parte, não só a cultura interna, mas também os e estilos personalistas de seus gerentes. Esta é uma realidade de grande parte das empresas e se aplica de maneira especial em pequenas e médias empresas (PMEs). Neste contexto, um aspecto que merece especial atenção é compreender como se dá a interação desses gerentes com o seu contexto social, ou na busca do conhecimento, e como isso influencia a tomada de decisão. A escolha de alternativas carregadas de altos níveis de incerteza não é novidade para os empresários. A redução de tais riscos e a escolha da melhor alternativa para seus negócios depende do alcance $e$ complexidade da decisão, da formação do decisor e da sofisticação dos recursos informacionais colocados à sua disposição.

Ao buscar informações para a redução da incerteza, o gerente assume o papel crucial de interpretá-las, de forma a dar-Ihes o significado necessário a uma boa decisão (CHOO, 2003; DAVENPORT, 2001; ROBERTS; CLARKE, 1989;). A ambigüidade inerente a esse processo não deve ser interpretada como uma ameaça e sim como um predicado enriquecedor. A partir de aparentes contradições existentes em algumas das fontes de informação disponíveis, este fluxo contribui para qualificar sua decisão, porque possibilita a criação de alternativas para a escolha final (MINTZBERG; RAISIGHANI; THÉORÉT, 1976), e através de um processo de síntese dessas informações (muitas contraditórias entre si) configura-se a dialética organizacional à qual se refere Nonaka e Toyama (2003), tendo como cenário o contexto sociocultural que envolve o espaço e o tempo da atividade empresarial.

A moderna literatura de gestão de negócios (DAMNPOUR, 1996; LAFORET; TANN, 2006; MAZZAROL, 2006) admite que as empresas, em especial as de menor porte, em fase de crescimento direcionado a mercados pouco conhecidos e mais sofisticados em suas exigências, passam, necessariamente, por mudanças gradativas no seu processo decisório. $O$ atual contexto informacional e as redes de informação que se estabelecem obrigam as empresas a investirem em um novo tipo de capacitação de seus gerentes, aumentando a demanda por sistemas mais eficazes de informação e a adotarem 
métodos mais estruturados para a tomada de decisões (JENNINGS; WATTAN, 1994; MINTZBERG; RAISIGHANI; THÉORÉT, 1976). A realidade econômica contemporânea que permeia as decisões do pequeno e médio empresário subverte conceitos clássicos de tempo e espaço, e traz uma nova reflexão sobre tudo o que já se disse ou foi estudado.

Este artigo tem como objetivo central apresentar uma proposta de pesquisa a respeito do comportamento e do uso do suporte informacional às decisões tomadas por empresários e gerentes de pequenas e médias empresas atuantes em arranjos produtivos locais (APLs). A investigação deverá focalizar aquelas ações voltadas para a inovação dos seus empreendimentos, vinculadas à sobrevivência de seus negócios. A partir de alguns dados a serem utilizados em uma pesquisa de doutorado, partimos do princípio de que a decisão pode ser vista como um processo socialmente construído a partir da informação compartilhada, no espaço físico e no contexto social de um aglomerado de empresas que caracterizam um APL.

A pesquisa proposta será desenvolvida por meio de entrevistas a serem realizadas com empresários do APL, escolhidos por uma amostragem intencional, dentre aqueles que tomaram decisões de inovação em suas empresas, nos últimos dois anos. A técnica será a de incidentes críticos, desenvolvida por Flanagan (1954). Questionários semiestruturados serão utilizados para orientar as entrevistas e foram concebidos a partir de um pré-teste realizado com alguns empresários do aglomerado. O estudo será feito com base nas seguintes categorias de análise:

1. Ambiente informacional e sua relação com mudança e inovação;

2. Fontes de informação e prioridades estabelecidas para seu uso no processo decisório;

3. Comportamento de uso da informação por parte dos gerentes e grau de relevância atribuído às informações oriundas dos sistemas de informação organizacionais;

4. Prioridades atribuídas pelos decisores a conhecimentos tácitos e explícitos;

5. As mudanças resultantes das decisões tomadas.

Além desta introdução, o presente artigo irá focalizar aspectos teóricos relacionados com o uso da informação no processo decisório em arranjos produtivos locais. 


\section{A INTERAÇÃO SOCIAL NA CONSTRUÇÃO DE UMA DECISÃO}

Inúmeros autores, representativos de diversos campos disciplinares (ALBAGLI; MACIEL, 2003; DOMINGUES, 2004; GIDDENS, 2003), nos levam a concluir que, em sua maioria, as ações individuais só podem ser devidamente explicadas e compreendidas dentro do contexto sociocultural onde as pessoas interagem. Nesse matiz sociológico, construído pela história da comunidade e sua visão de mundo, atenção especial deve ser dada àquilo que Johnson (1995) chama de aspectos "não materiais da cultura", tais como atitudes, crenças, valores e normas.

Uma melhor compreensão dessa realidade exigiria, ainda, a incorporação de elementos da "historicidade" do sujeito, uma vez que "[...] qualquer fenômeno social, cultural ou político é histórico e só pode ser compreendido dentro da história, através da história, em relação ao processo histórico [...]" (LÖWY, 2003, p. 76).

Nossa conviç̧ão, apoiada pelos conceitos e princípios acima apresentados, é que uma decisão constitui um caso particular do uso do conhecimento pessoal em um contexto organizacional. Uma análise do processo decisório, portanto, deve levar em conta o contexto social e da história de seus atores e, sobretudo, o entendimento dos processos pelos quais suas práticas sociais são institucionalizadas. Igualmente, não se pode apreender a importância das informações e do comportamento informacional do gerente sem uma adequada percepção de como essas informações fluem pela sua rede de contatos pessoais e se transformam, na seqüência, no conhecimento que irá fundamentar suas decisões.

Este ciclo de conhecimento, a partir de um estoque existente (NONAKA, 1996; GIDDENS, 2003; SHULTZEN et al., 2004) tem como elemento dinâmico a renovação constante propiciada pela informação (CARDOSO, 1994). Seguindo esta linha de raciocínio, é preciso compreender a totalidade do fenômeno informacional, a partir de suas conexões com a estrutura social e as vivências históricas de seus protagonistas (CARDOSO, 1994).

A informação, para Gómez (2000, p.3), "designa um fenômeno, processo ou construção vinculado a diversas 'camadas' ou 'estratos' de realização". Este fenômeno se materializa em traços culturais, constituindo-se no que a autora chama de "ação de informação". Quando utilizada como elemento redutor da incerteza (QVORTRUP, 1993), a informação assume o caráter dinâmico do conhecimento ou, como definido por Capurro (2003), ela é o próprio conhecimento em ação. É, Capurro (2003, p. 8), ainda, que reforça claramente 
a idéia da importância da conexão dos fluxos informacionais, na concepção mais abrangente do chamado paradigma social "[...] que não permite que a informação seja isolada do sujeito cognoscente, [...] deixando de lado os condicionamentos sociais e materiais do existir humano".

O processo interativo da informação, a partir do ambiente informacional e dos seus usuários, é visto por Dantas (2006, p. 25) como "uma espécie de sítio intermediário entre a origem dos fenômenos sinalizadores e os agentes que os captam e os processam. Não será nem atributo do objeto, nem do agente, mas será sempre uma relação entre ambos".

Em suma, a busca pela informação está associada a uma percepção do seu significado - só assim ela será informação - que, por sua vez, constrói o conhecimento organizacional e possibilita a ação e, conseqüentemente, a decisão. Investigar este caminho, num contexto dos empresários do APL de Nova Serrana, requer ainda outros suportes teóricos.

\section{O ARRANJO PRODUTIVO DE NOVA SERRANA}

Segundo o SEBRAE (2004, p. 9) um arranjo produtivo local pode ser definido como:

Um tipo particular de 'cluster' formado por pequenas e médias empresas, agrupadas em torno de uma profissão ou de um negócio, onde se enfatiza 0 papel

\begin{abstract}
desempenhado pelos relacionamentos - formais e informais - entre empresas e demais instituições envolvidas. As firmas compartilham uma cultura comum e interagem, como um grupo, com o ambiente sociocultural local.
\end{abstract}

Os modernos APLs podem ser vistos como uma versão pós-moderna da medieval instituição econômica, dominante no século XVI e conhecida na literatura da história como "putting-out system", ou sistema de manufatura doméstica. Com este sistema surgem as corporações da idade média, nas quais predominava a produção doméstica de subsistência. Esse tipo de produção, ao romper com o mecanismo feudal da corvéia, propicia uma comercialização impulsionada pelos primeiros mascates e intermediários que se estenderia aos mercados fora da sua micro região de influência.

Configurou-se assim uma evolução natural, mediante a qual um processo totalmente artesanal, baseado na estrutura tradicional "mestre-aprendiz", deu origem aos primeiros indicadores do sistema capitalista moderno, ainda que incipiente. $\mathrm{O}$ antigo mestre passou a assumir as funções de um rudimentar empresário e "passou a ter a propriedade das máquinas e instrumentos de trabalho e, freqüentemente, do prédio no interior do qual a produção se realizava". (HUNT; SHERMAN, 1978, p. 27). 
Modernamente, conforme Santos, Crocco e Lemos (2003), existem dois tipos de APLs. O primeiro é constituído dos chamados "arranjos de subsistência" e o outro é o tipo "centro radial". No Brasil, exemplos do primeiro tipo de APL são os pólos calçadistas de Nova Serrana (MG) e de Franca (SP), bem como o pólo têxtil, de vestuário e calçados de Itajaí (RS). Um exemplo do segundo é o conjunto de pequenos fornecedores de uma grande montadora de automóveis, como é o caso do complexo de fornecedores da FIAT (MG) e da EMBRAER em São José dos Campos (SP). O presente trabalho irá focalizar este primeiro tipo de APL, que é a classificação do Arranjo de Nova Serrana, o campo escolhido para nossa pesquisa.

Situada em Minas Gerais, distante $112 \mathrm{~km}$ de Belo Horizonte, a cidade de Nova Serrana ganhou notoriedade pelo desenvolvimento de um parque calçadista, hoje formado por mais de 800 empresas de micro, pequeno e médio porte. Trata-se, portanto, uma economia de aglomeração, caracterizada pela literatura como um APL (LASTRES; CASSIOLATO, 1999; SANTOS; CROCCO; LEMOS, 2003, SEBRAE, 2004, SUZIGAN; GARCIA; FURTADO, 2003).

Segundo o Instituto Euvaldo Lodi o APL de Nova Serrana é o terceiro principal pólo calçadista do Brasil em número de fábricas, com características marcantes de produção de calçados esportivos e respondendo por $55 \%$ da produção brasileira de tênis.

A descrição de como se constituíam as rudimentares empresas de manufatura doméstica na idade média se ajusta à maioria das empresas de Nova Serrana. O relato feito por Susizan, Garcia e Furtado (2003) sobre a formação de Nova Serrana, bem como as pesquisas feitas sobre a gênese de outros aglomerados, parecem confirmar esta semelhança.

\section{ALGUNS RESULTADOS PRELIMINARES}

Nas primeiras entrevistas com empresários locais, foram observados alguns fatos constitutivos do conceito de interação social que ocorrem naquele espaço econômico, fortemente impregnado pela cultura da comunidade, formadores de um cenário e do contexto social onde se desencadeiam as grandes decisões do empresariado local.

Para delimitar nosso campo de observação nós o situamos dentro de um conceito mais específico, que passará ser denominado "ambiente informacional do APL" (AIA), o AIA se caracteriza por fluxos informacionais que alimentam as redes pessoais. O uso dessas redes como referência para monitorar seus negócios são práticas costumeiras e 
institucionalizadas pelos pequenos empresários da região.

Estudiosos desses arranjos, especialmente os da Rede de Pesquisas em Sistemas Produtivos e Inovativos Locais-RedSist, instituição de pesquisas brasileira votada para análises socioeconômicas de arranjos produtivos, pesquisam esses fluxos de informações e seus elos. Assim, as interações entre os atores são geradoras de um estoque de conhecimento, basicamente tácito, que determina e são determinados por fortes traços culturais. Rapini et al., definem essas redes pessoais da comunidade como:

Os fluxos de informações que circulam no interior de arranjos produtivos estão associados a relacionamentos interpessoais entre indivíduos ou grupos, que possibilitam uma transmissão mais efetiva de conhecimentos 'tácitos', os quais são 'codificados' a partir do próprio arranjo. Quanto mais 'tácito' for o conhecimento requerido para viabilizar o processo inovativo, maior será a necessidade de estruturarem-se canais diretos de contato e comunicação, que permitam um intercâmbio sistemático de informações entre os agentes integrados ao arranjo (2004, p. 3).

O ambiente informacional do APL estabelece uma prática comunitária que ultrapassa as fronteiras de cada empresa e exerce grande influência nos fluxos de informação (RAPINI et al., 2004; SUSIZAN; GARCIA; FURTADO, 2003) que constituem a substância do processo decisório de cada empresário local. Assim, sob o ponto de vista informacional, o APL pode ser concebido como um espaço social onde se localizam e circulam as informações provenientes de clientes, fornecedores, parceiros, consultores, entidades de apoio (governo, universidades, sindicatos, entidades de classe).

Essas informações encontram-se incorporadas em sistemas de informação organizacionais, na mídia local ou em outras empresas do arranjo, além de serem disseminadas informalmente no contexto dos negócios das empresas ali localizadas. Tais personagens, notadamente os clientes, fornecedores e outros empresários locais (às vezes, na figura do seu potencial concorrente), são os principais atores envolvidos neste cenário pois compartilham, de alguma forma, algumas das decisões mais importantes dessas empresas e estabelecem um matiz sociológico que extravasam os limites privados de uma empresa. Aqui poderíamos lembrar de Shera (1971) ao tentar desenvolver as bases para uma "epistemologia social", dentro da ciência da informação. Segundo suas palavras este seria um campo propício ao estudo do conhecimento humano, que fosse além dos experimentos laboratoriais de psicólogos em cima de indivíduos, da compreensão de seus 
comportamentos mentais e das teses de sociólogos, cujo campo de observação se restringe aos comportamentos grupais, sem maiores aprofundamentos na forma com essas relações se estruturavam. Ele advogava uma visão teórica mais próxima daquilo que foi conceituado como paradigma social da ciência da informação. Em 1970, no $88^{\circ}$ Encontro Anual da American Society for Information Science, em Philadelphia, Estados Unidos, declarava "[...] a transferência da informação [...], mesmo quando expressa em equações matemáticas ou máquinas, ainda é um produto da sociedade, do homem trabalhando coletivamente em grupos em buscas de algumas finalidades" (SHERA, 1971, p. 77).

\section{PROCESSO DECISÓRIO}

O resultado mais visível e estudado pelos pesquisadores da chamada sociedade da informação, a partir do notável desenvolvimento das tecnologias da informação e da comunicação (TICs), reside no rompimento do paradigma, até então predominante, de tempo e espaço. $\mathrm{Na}$ construção da sua Teoria sobre a Estruturação Giddens (2003; p. 14) enfatiza a importância dessas variáveis na constituição do sujeito e da sociedade, especialmente a partir de práticas repetitivas do cotidiano - o que ele chama de "caráter recursivo", ou seja, a rotina da vida social. Nas suas palavras "as práticas sociais, ao penetrarem no espaço e no tempo, estão na raiz da constituição do sujeito e do objeto social". E mais ainda: "a rotinização é vital para os mecanismos psicológicos por meio dos qual o senso de confiança ou de segurança ontológica é sustentado nas atividades cotidianas da vida social". (GIDDENS, 2003, p. 26, grifos nossos).

Tais idéias, elementos basilares da sua teoria, são importantíssimas para apoiar nossa tese de que a decisão é o resultado de um processo social, nos limites históricos e sociológicos de um APL e de seus empresários e podem ser confrontados com os novos parâmetros de espaço e tempo da era global. Ainda explorando a questão do tempo e do espaço, Giddens (2003, p. 441) fornece outro conceito, 0 do 'distanciamento tempo-espaço', por ele entendido como "a extensão de sistemas sociais através do tempo-espaço, com base nos mecanismos de integração social e de sistema”.

Ainda, dentro das idéias deste sociólogo inglês há dois conceitos fundamentais para a presente argumentação: a consciência prática e a consciência discursiva. O primeiro é definido pelo autor como aquilo que

Os agentes fazem e por que o fazem - sua cognoscitividade como agentes [...] consiste em todas as coisas que os atores conhecem 
tacitamente sobre como 'continuar' nos contextos da vida social sem serem capazes de lhes dar uma um expressão discursiva direta (GIDDENS, 2003, p. 25).

Já o conceito chamado por ele de consciência discursiva é "o que os atores são capazes de dizer, ou expressar verbalmente, acerca das condições sociais, incluindo especialmente as condições de própria ação; consciência que tem uma forma discursiva" (GIDDENS, 2003, p. 440).

Lastres (2003) chama a atenção para o fato de que as teorias econômicas tradicionais sempre relegaram a questão espacial em suas interpretações sobre os fenômenos econômicos, reservando apenas alguma importância a esta variável, quando se tratava de analisar a economia regional. Com o advento da Sociedade da Informação e o avassalador processo de globalização, as noções de tempo e espaço foram pulverizadas pelo avanço tecnológico no campo da informação e da comunicação. De fato, não existem hoje, na prática, como avaliá-las, a partir de tradicionais modelos econômicofinanceiros, como determinavam os antigos cânones da economia.

Hoje, indústrias de grande porte, volume de produção ou sofisticação tecnológica, não enfrentam quaisquer barreiras espaciais e nem dependem da proximidade de mercados, da oferta de mão-de-obra local ou massa crítica de conhecimento espacialmente localizado.

De fato, as modernas tecnologias superam, em grande parte, eventuais dificuldades de fatores locacionais e viabilizam os empreendimentos, teoricamente, em qualquer parte do mundo, numa outra concepção de temporalidade.

Graças a essas tecnologias atuais e as grandes redes de conexão via Internet, as empresas resolvem a quase totalidade dos problemas advindos dos fluxos financeiros, o combustível que dá velocidade ao capitalismo. Assim, os reflexos da velocidade e simultaneidade da informação na estrutura da sociedade atual são profundos.

Embora haja todo um elenco de argumentos para saudar este grande avanço na qualidade de vida do ser humano e na eficácia dos negócios, há também vozes, com as de Bauman (1999) e de Dupas (2005), que advertem para os riscos que essas transformações apresentam para sociedades diversificadas e injustas.

E é neste quadro, que se dá a grande contradição do contexto social no qual se insere o empresário que atua em um APL. Este tipo de empresário, sobrevivente em um mercado cada vez mais globalizado, tenta adaptar-se a uma veloz e alucinante corrida de inovações tecnológicas e mudanças nos padrões de comportamento ético. Como terreno seguro, ele conta 
apenas com a sua história de vida, apoiada em valores da sua estrutura social, construída ao longo das várias gerações que se sucedem nos seus pequenos negócios.

Assim, a pesquisa objetiva analisar suas decisões que buscam inovações como garantia da sobrevivência e desenvolvimento de seus negócios (ALBAGLI, $\quad 1999 ; \quad$ LASTRES; CASSIOLATO, 1999; SUSIZAN; GARCIA; FURTADO, 2003; LOPES; LUGOÑES, 1999). É preciso, entretanto, compreender o conceito de inovação dessas empresas, a partir do impacto da natureza e do alcance de seus resultados no seu modo de produção. Neste sentido, a inovação em PMEs pode ser caracterizada pela definição de Lemos (1999, p.126). Para esse autor, inovar é

O processo pelo qual os produtores dominam e implementam o projeto e a produção de bens e serviços que são novos para os mesmos, a despeito de serem ou não novos para seus concorrentes.

Diversos exemplos dessas inovações são apresentados pelos estudos patrocinados pela RedeSist. Para Susizan, Garcia e Furtado (2005, p.113), por exemplo, "são [...] comuns as visitas para 'ver máquinas novas' e troca de idéias e informações". Ou seja, a máquina nova adquirida por um vizinho pode provocar vários processos decisórios de empresários locais, envolvendo a compra de maquinário semelhante, conforme atestam alguns entrevistados.

Outros participantes da fase inicial da pesquisa indicaram que só se motivaram a inovar quando estimulados pelo recebimento de um pedido que ultrapassava a sua capacidade atual de produção. Neste caso, as máquinas novas são vistas apenas como um instrumento de mudanças incrementais na linha de produção.

No APL de Nova Serrana são raros os exemplos de inovação de produtos. O mais característico é o comportamento reativo do empresariado local, que simplesmente se abastece de informações sobre novos modelos e tendências de moda. Conforme depoimentos do atual presidente do sindicato patronal e de alguns dos empresários entrevistados, essas informações são, por ordem de importância: notícias e comentários transmitidos aos empresários por seus representantes de vendas, notícias sobre lançamentos de novos produtos por grandes marcas através de fontes eletrônicas e, por último, contatos realizados em eventuais participações em feiras e encontros de negócios.

Os elementos acima demonstram que constitui prática generalizada no APL de Nova Serrana, copiar e adaptar modelos às condições e conhecimento técnico de cada produtor, o que coincide com a visão de 
Susizan, Garcia e Furtado (2003). Outra vertente da inovação, ainda de caráter incremental (LEMOS, 1999), é trazida pelos fabricantes fornecedores de solado e cabedal, que são os componentes fundamentais na inovação de modelos em calçados esportivos e tênis. Atribuem-se a esses fornecedores a responsabilidade pela introdução da novidade tecnológica que direcionaria as linhas de produção para os novos modelos. Essas interações entre fabricantes e fornecedores são fortes indicadores da ocorrência e existência de decisões de inovação que são compartilhadas ao longo da cadeia produtiva do APL.

Observa-se que o gerente principal de uma PME geralmente, é o próprio dono do negócio ou sócio da empresa. Esses gerentes, em sua grande maioria, ressentem-se de um maior preparo para a atividade gerencial, seja em decorrência de seu baixo nível de escolaridade ou devido ao fato de não terem recebidos qualquer preparação técnica formal para 0 desempenho de suas funções. Esses resultados preliminares coincidem com as observações de Susizan, Garcia e Furtado (2003, p. 112), para quem "a maioria dos novos empresários é oriunda das linhas de produção das empresas locais, [...] o que explica, em grande parte, as dificuldades de gestão das novas empresas".
Tais aspectos do perfil da maior parte dos gerentes que foram objeto de estudos em nossa pesquisa ajudam a explicar suas práticas gerenciais e a identificar suas decisões como sendo apoiadas num processo social a partir da informação e do conhecimento compartilhado no ambiente informacional do APL. Evidencia-se assim o tipo de conceito de rede social, conforme descrito por Tomaél (2005), o qual assume o caráter metafórico explicitado por Alcará et al. (2006). Essas características do processo decisório no contexto do APL constituem peças chaves para a compreensão das decisões desses atores, os quais são profundamente influenciados pela tradição de seus ofícios e sua ética familiar. É, no contexto dessas redes sociais, que os decisores buscam a segurança de suas decisões.

\section{PROCESSO DE CRIAÇÃO DE CONHECIMENTO ORGANIZACIONAL QUE SUPORTA A DECISÃO}

A primeira categoria de análise a orientar o presente trabalho refere-se ao ambiente informacional do APL e sua relação com a mudança e com a inovação. Neste sentido, será utilizado como aporte teórico o conceito de "ba", desenvolvido a partir da Teoria da Criação do Conhecimento Organizacional (NONAKA; TAKEUCHI, 1997), e revisto por Nonaka e Toyama (2003) a partir das idéias da teoria da estruturação de Giddens (2003). Esses 
autores introduziram três idéias sobre o processo de criação de conhecimento organizacional, que são o conceito de processo dialético - que preferimos chamar de dialética organizacional, o conceito de transcendência e o processo de síntese. $\mathrm{O}$ conceito de "ba" foi traduzido por outros autores como "contexto capacitante" (ALVARENGA NETO; BARBOSA; CENDON, 2006). Na definição de Nonaka e Toyama (1998) (apud NONAKA; TOYAMA, 2003), o "ba" é:

Um espaço compartilhado para relacionamentos emergentes. Este espaço tanto pode ser físico (p.ex. escritórios, lugares dispersos no ambiente de negócios, etc.), virtual (p.ex. e-mail, teleconferência), mental (experiências, idéias ,ideais) ou qualquer combinação entre eles. $O$ que diferencia $\mathrm{o}$ ba de uma interação ordinária humana é o conceito de criação de conhecimento.

Esses autores adaptaram o conceito de transcendência para a realidade organizacional, sob o prisma do conhecimento. Assim,

A criação de conhecimento é um processo transcendente as entidades (indivíduos, grupos, organizações, etc.), ultrapassando as fronteiras do velho e do novo e dentro de si mesmo para a aquisição de novos conhecimentos. No processo, novos artefatos conceituais e estruturas para a interação são criados, o que amplia novas possibilidades, bem como enquadram as entidades na conseqüente criação de ciclos de conhecimento. Assim, as entidades coexistem com o ambiente porque elas são sujeitas às influencias ambientais, assim como o ambiente é influenciado por elas. (NONAKA; TOYAMA, 2003, p. 2).

Transcender significa então, ultrapassar os limites organizacionais. E isto fundamenta o conceito da interação, dentro do ambiente informacional do APL (meio), entre o gerente de uma PME (sujeito) e o objeto de sua ação (a decisão). No contexto capacitante - que para nossa argumentação é o próprio ambiente informacional do APL - o processo decisório ocorre de maneira compartilhada entre os diversos atores, cada um com suas próprias conexões socioculturais e estruturas cognitivas.

É o contexto capacitante do APL - ou seu "ba" - que estrutura e possibilita a conversão das informações predominantemente tácitas em conhecimentos codificados. Esse contexto, portanto, estabelece uma referência visível e invisível para a rede social, da qual Giddens (2003; p. 26) fala com muita propriedade: "os locais não são apenas lugares, mas cenários de interação [...] os cenários são usados cronicamente - e, em grande parte, de maneira tácita - por atores sociais para confirmar o significado em atos comunicativos".

Como visto anteriormente, o processo decisório é um caso particular de uso do conhecimento organizacional que transcorre dentro da rede sociológica do APL, especialmente se esse processo 
conduz a uma inovação, por mais simples que seja. O contexto capacitante do APL, onde fluem conhecimentos tácitos e explícitos - mais aqueles do que estes - é a manifestação coletiva mais visível do que Giddens chamou de consciência prática (conhecimentos tácitos) e consciência discursiva (conhecimentos codificados, explícitos). A produção desses conhecimentos constitui indiscutível processo interativo entre objeto (ambiente informacional), seu meio (rede sociológica do APL) e o indivíduo demandante (o gerente, sujeito e ator principal da decisão), tendo como matéria prima, a informação. Conforme Nonaka e Toyama (2003, p.4),

A (consciência) discursiva nos dá a racionalidade para as ações e referem-se ao mais consciente e explícito conhecimento teórico. Já a (consciência) prática se refere ao que nós realmente pensamos ou teorizamos. Neste sentido, podemos dizer que o conhecimento tácito é produzido por nossa consciência prática e o conhecimento explícito é fruto de nossa consciência discursiva.

A segunda e terceira categorias de análise a orientar o presente estudo são as fontes de informação utilizadas pelo decisor e o seu comportamento no uso desta informação. Admitindo-se o conhecimento organizacional como um processo dialético, o seu resultado é aquilo que nós denominamos como "a dialética organizacional”. Tal processo é conceituado por Nonaka e Toyama (2003, p. 1) como aquele

No qual várias contradições são sintetizadas, através das interações dinâmicas entre os indivíduos, a organização e o meio ambiente. $\mathrm{O}$ conhecimento é criado em espiral que flui através de conceitos aparentemente contraditórios, assim como a ordem e o caos, micro e macro, parte e todo, mente e corpo, tácito e explícito, em si mesmo e no outro, dedução e indução, e criatividade e eficiência. Nós argumentamos que a chave do entendimento do processo da criação de conhecimento é o pensamento e a ação dialéticos, que transcende e sintetiza cada contradição. A síntese não é compromisso, aceitação. Ao contrário, é a integração de aspectos opostos através do processo dinâmico de diálogo e prática.

Parte das contradições a que se referem estes autores, está presente na ambigüidade da informação, tema exaustivamente tratado por vários pesquisadores da ciência da informação e de outros campos teóricos (CHOO, 2003; GADALETA et al., 2005; LASTRES, 1999; ROBERTS; CLARKE, 1989; WEICK, 1973; YANG-WOO, 2003;).

As contradições são componentes importantes dos níveis de incerteza, que têm como indicadores as probabilidades de sucesso e fracasso das decisões, notadamente as de inovação. A incerteza ou ambigüidade são componentes intrínsecos do fluxo de informações que é gerado no contexto do ambiente informacional interno ou externo à 
empresa. As múltiplas interpretações e a busca do significado no contexto desse fluxo produzem um conhecimento, que paradoxalmente, pode reduzir o grau de incerteza e ambigüidade da decisão e propiciar uma escolha mais eficaz dentre as alternativas contempladas. Trabalhar a ambiguidade é também trabalhar com as contradições.

As contradições organizacionais se referem ao olhar mais interno à organização e aos diversos significados que as organizações e indivíduos atribuem a um fenômeno a partir do seu próprio contexto sociocultural e histórico. Essas contradições também produzidas pelo confronto entre a concepção formada pela empresa sobre determinados assuntos e a realidade construída a partir do ambiente informacional.

Aqui, a contradição, deve ser circunscrita a um fenômeno de natureza basicamente social. A sociologia apresenta um sentido para este termo que incorpora, em parte, também o pensamento marxista, sintetizados, respectivamente, nas palavras de Johnson (1995, p. 56), para quem "[...] qualquer ocorrência em que dois ou mais aspectos de um sistema social são incompatíveis ou se conflitam uns com os outros." A esse propósito, para Löwi (2003, p.17) a contradição é um elemento do método dialético, cujo campo de aplicação está na análise das contradições da realidade, onde se desenrola um "enfrentamento permanente entre as ideologias e as utopias na sociedade [...]".

Para Nonaka e Toyama (2003) as contradições dentro da organização podem ser fruto do confronto entre conhecimentos tácitos e conhecimentos explícitos, entre rotina e teoria e entre recursos internos e o ambiente externo à organização. Situandoa no escopo da decisão, entendemos a contradição organizacional como um conjunto das diferentes interpretações feitas a partir e pelos indivíduos, dentro de uma organização, incrustadas nas diversas alternativas possíveis para a tomada de uma decisão.

O olhar de cada elemento dentro e fora da organização é, por sua vez, influenciado pelos respectivos contextos socioeconômico e a sua própria historicidade. $\mathrm{O}$ resultado do processo da dialética organizacional é a síntese de um processo apropriado pelo gerente em sua decisão final, e pode ser compreendido nas palavras de Rendón Rojas:

Para se produzir o conhecimento é indispensável realizar não só a estruturação e interpretação de símbolos, senão outra série de atividades mais completas. [...] a decodificação de símbolos, senão a memorização, a análise, que permite identificar os elementos constitutivos do que se está conhecendo e suas relações com as partes do todo, a síntese com a qual se volta a reunirem-se em um todo, aquilo que se fragmentou e descobrir as relações do todo com 
as partes, tendo uma visão dialética, que permita descobrir a interconexão da informação nova com outras informações e conhecimentos do sujeito cognoscente, elaborar, inferências de vários tipos como interferências dedutivas, indutivas, abdutivas e hermenêuticas. (RENDÓN ROJAS, 2005, p. 53-54).

A seguir, serão desenvolvidos os argumentos referentes à quarta categoria de análise, que tem como objetivo compreender a visão desses empresários a respeito da importância relativa por eles atribuída aos conhecimentos tácitos e explícitos no contexto da tomada de decisões referentes à inovação.

\section{O PRODUTO SOCIAL DA DECISÃO: $O$ COMPARTILHAMENTO DA INFORMAÇÃO E DO CONHECIMENTO}

A vasta literatura sobre gestão de empresas e organizações já abordou o fenômeno da decisão sob diversos ângulos, a partir de variadas tipologias, estilos de lideranças, arranjos estruturais e tantos outros. O processo decisório é uma sucessão de etapas de processos mentais, materializado em ações cujo ápice é a escolha de uma alternativa, com finalidade básica de resolver um problema, contornar uma crise ou tirar proveito de uma oportunidade (MINTZBERG; RAISIGHANI; THÉORÉT, 1976).

Há um relativo consenso no sentido de que a tomada de decisão envolve a escolha de alternativas e há autores que defendem que qualquer decisão é a resultante de diversas decisões parciais (CHIAVENATO, 2006). A literatura também já consagrou uma forma de classificar as decisões em decisões programáveis (ou de rotina, mais operacionais ou táticas) e não programáveis, em geral as que são de natureza mais estratégica (MINTZBERG; RAISIGHANI; THÉORÉT, 1976).

A despeito dos grandes avanços oferecidos pela tecnologia, o que prevalece ainda entre os teóricos da administração, é o princípio da racionalidade limitada, aplicável à grande maioria das decisões. Esse princípio foi desenvolvido a partir dos trabalhos de Herbert Simon (1979) em meados do século passado.

A parcela "não racional da decisão" tem sido abordada em outras áreas das ciências humanas, como a psicologia, a educação, filosofia e a sociologia. A ciência da informação tenta estudar este fenômeno, em especial sob a perspectiva dos estudos sobre necessidades, busca e uso da informação por parte de executivos em contextos organizacionais (AGUIAR, 1991, AUSTER; CHOO, 1991; BARBOSA, 1997; KHULTHAU, 1999).

Para Khulthau (1999, p.399), “a primeira tarefa dos executivos é fazer julgamentos e tomar decisões para alcançar seus objetivos." A busca da informação para reduzir a incerteza guarda um grande paralelismo com os estágios do processo decisório, propostos por 
Mintzberg, Raisichani e Théorét (1976) para descrever decisões não programáveis, como é o caso da maioria daquelas voltadas à inovação. $A$ exploração das fontes do ambiente informacional está na mesma linha de desenvolvimento do processo decisório, naquela fase que chamaríamos de seleção de alternativas.

O uso de sistemas mais avançados de informação pelos gerentes do APL depende do grau de desenvolvimento, dos recursos e de sua visão empresarial, o que na maioria dos casos são limitados e rudimentares. Por exemplo, o mais comum são anotações manuscritas do andamento dos negócios, conforme ouvimos dos nossos primeiros entrevistados. Esse resultado é condizente com o estudo de Freitas (1996) que, a partir de uma investigação realizada em pequenas empresas do setor metalúrgico em Minas Gerais, constatou a importância das anotações pessoais como fonte de informação no ambiente empresarial. Outro aspecto importante do comportamento informacional dos gerentes do APL de Nova Serrana, e que é confirmado no estudo de Rapini et al. (2004), é o fato de as informações trocadas com clientes, fornecedores e firmas do mesmo setor serem consideradas pelos gerentes como as mais importantes no contexto das decisões de inovação.
As fontes pessoais de informação foram destacadas como as de maior importância pelos empresários entrevistados. Esse resultado é também salientado em estudo desenvolvido por Lu (2007). Ele destaca o fato de que as pessoas ao possuírem maior credibilidade, serem mais facilmente acessíveis, são capazes de oferecer a informação de maneira mais contextualizada e podem, em muitas situações, transmitir informação de alto valor agregado, contribuindo assim para minimizar a sobrecarga informacional do receptor.

Em suma, é este o conjunto de resultados que emerge a partir deste estudo preliminar realizado dentro do APL de Nova Serrana. Ou seja, é um contexto decisório propiciado pela informação compartilhada, no qual as decisões constituem fruto e produto social deste ambiente. De fato, com base nas respostas obtidas a partir das entrevistas já realizadas, conforme a técnica do incidente crítico, fica claro que todos os empresários entrevistados recorrem, sem exceção, às informações que circulam no APL como referencial primário para suas decisões. Tais informações são colhidas e interpretadas e os conhecimentos resultantes, compartilhados com os atores da rede social do APL. Esses elementos, em interação com o conhecimento e a 
experiência pessoal do gerente constituem o ingrediente final do processo decisório.

Os processos acima descritos podem ser exemplificados por meio de três casos, obtidos na nossa coleta preliminar de dados. Na empresa $A$, seu proprietário e seu sócio (sua filha) perceberam sinais alarmantes de declínio de vendas em sua linha de calçados infantis. Imediatamente, eles começam a discutir possíveis soluções para a sobrevivência do negócio. Suas preocupações foram compartilhadas com seus empregados e a eles foram pedidas soluções. Paralelamente a essa sondagem interna, iniciou-se também um processo de consulta a vários empresários do APL sobre a possibilidade de diversificação da linha de produtos da empresa. Ao longo desse processo foram obtidas opiniões contraditórias; ou seja, enquanto alguns colegas empresários indicavam uma direção, os representantes de vendas apontavam para outro sentido e outras perspectivas, ainda eram sugeridas pelos empregados.

Ajudado pelos mais experientes operários de sua fábrica e pelas informações ouvidas da sua rede pessoal de contato, o empresário tomou a decisão de desenvolver uma linha piloto de calçados masculinos adultos, que veio a representar, alguns meses mais tarde, a sobrevivência de seus negócios. Com novas máquinas, esta é hoje sua linha mais lucrativa, o que the permite planos para, em seqüência, implantar a produção de calçados adultos femininos.

Em entrevista, o empresário afirmou que, embora atribua boa parte de suas ações à sua experiência, estima que seus inúmeros contatos pessoais dentro da comunidade do APL, bem como as idéias de seus empregados, foram decisivos na escolha do caminho a ser seguido.

O segundo caso, a empresa $B$, envolveu a decisão de desativar parte da produção que havia gerado uma mudança radical não só na empresa, mas no próprio núcleo familiar do empresário. Este, dos mais antigos e tradicionais do aglomerado, percebeu que a empresa passava por um crescente e alto índice de inadimplência dos seus clientes. Essa situação decorria do fato de a empresa ter concentrado sua carteira nas mãos de poucos clientes e isto resultou em dívidas quase impagáveis. $O$ empresário então consultou seus filhos e esposa e, depois de "sofridas discussões" chegou ao consenso de que seu "nome na praça" era o mais importante. Assim, com o respaldo familiar, encontrou-se uma saída, que envolveu a formação de uma nova clientela, mais pulverizada e com outro tipo de produto. O proprietário da empresa $B$ dedicou-se então ao desenvolvimento desse novo mercado consumidor, reativando seus antigos contatos pessoais, construídos ao longo de sua carreira de 30 
anos como vendedor. A recuperação da empresa envolveu o estabelecimento de novas encomendas, bem como a venda de parte do maquinário antigo para os próprios empregados, que assumiram parcela da produção. Foram adquiridas máquinas mais adequadas aos novos consumidores e o resultado de todo esse processo foi a recuperação financeira da empresa, ainda que num patamar de produção bem abaixo do anterior. Nas palavras do proprietário da empresa $\mathrm{B}$, sua decisão foi o resultado do "conselho de família", da sua "rede pessoal de contatos" e da "solidariedade" da comunidade do APL de Nova Serrana. Além do mais, o empresário pôde continuar a propiciar renda a seus antigos empregados, agora responsáveis por parte da sua produção terceirizada.

O terceiro exemplo vem de uma empresa de maior porte, aqui denominada empresa $C$, que faz parte de um conjunto de outras seis empresas, pertencentes à mesma família. Ao receber uma consulta sobre possibilidades de exportar sua produção, decisão que implicaria investimentos expressivos em maquinário e treinamento, o proprietário recorreu ao conselho de seus irmãos, sendo um deles seu sócio. Expôs, também, a sua situação a seu empregado mais antigo e chegou a avaliar a segurança deste empreendimento com vários empresários amigos. Depois de ter feito "uns cálculos", o empresário revelou que a decisão final saiu de uma síntese dessas opiniões. A solução envolveu a aquisição do novo maquinário, com base na confiança em seu mais antigo empregado, que se encarregaria de treinar seus operários no uso desta nova tecnologia de produção. Ou seja, até o suporte para disseminar a nova tecnologia encontra uma sustentação na própria rede social tecida em torno do arranjo, uma forma muita mais simples de conversão de conhecimentos "explícitos - tácitos explícitos".

Outro importante elo dessa rede sociológica está na interação dessas pequenas empresas com os fabricantes de matrizes de solados e cabedais. Suzigan, Garcia e Furtado (2005, p.114) relatam que

É a interação com os fabricantes de matrizes e com as empresas especializadas na injeção de solados que se revela de importância estratégica. Não só porque envolve a proteção de conhecimentos sobre novos tipos e 'designs' de solado, como também porque é preciso estabelecer relação de confiança entre as partes [...].

Assim, lembrando as palavras de Shera (1971) sobre a importância do trabalho coletivo vale ser mencionada ainda, a prática já consolidada do associativismo dentro do $\mathrm{APL}$, prática essa desenvolvida pelo sindicato patronal local, o SINDINOVA. A imagem dessa instituição, além da forte componente de 
representação política, materializa institucionalmente o arranjo (a maioria dos empresários não sabem o que é $A P L)$ e estrutura um ambiente informacional na comunidade, cuja rede ("radio peão" no jargão local) assim é reconhecida, legitimada e identificada. $O$ sindicato patronal é, portanto, o canal partilhador e veiculador de informações, o porta voz das demandas coletivas dos integrantes do APL. É o fórum das discussões e a estrutura aglutinadora das informações que chegam através dos "raconteurs" sociológicos, termo este cunhado por Giddens para se referir aos mensageiros de informações, ou "mexeriqueiros sociológicos", que se espalham pelos diversos espaços públicos e privados da comunidade. Nessas redes sociais nascem decisões que, de forma direta ou indireta, acabam resultando na a construção coletiva de uma comunidade e possibilitam a sua sobrevivência em um mercado cada vez mais exigente e ambicioso.

Por meio da investigação das características específicas do APL de Nova Serrana, pretende-se explorar a quinta categoria de análise, qual seja avaliar os efeitos das mudanças introduzidas nas empresas como resultado de processos decisórios compartilhados com vistas à introdução de inovações.
8 CONCLUSÕES

Uma das grandes finalidades do ser humano é a realização dos grandes objetivos pessoais e das organizações às quais pertencem. Busca-se a realização pessoal e o reconhecimento da estrutura social, o que implica, neste ambiente, a sobrevivência de negócios e empregos, que dependem fundamentalmente de tomada de decisões ancoradas em referências históricas e culturais da sociedade que lhe dá suporte institucional. A missão do empresário, especialmente o da pequena e média empresa, é de forte cunho social, dado a repercussão de seus atos em benefícios coletivos.

O tempo já não traduz o sentido natural da evolução cronológica, mas dita a urgência e a simultaneidade, que mata a diversidade, impede o desenvolvimento da identidade e liquida as noções tradicionais de espaço. A competição moderna imposta pela concorrência aética e despersonalizada, massacra traços culturais, noções de coisa pública e cidadania. Sofremos a pressão constante de novos padrões capitalistas que não têm nenhuma pátria e apenas obedecem à "mão invisível” do mercado.

Modelos de gestão são concebidos para que eles se apossem cada vez mais dos conhecimentos pessoais e dos estratos sociais capazes de reproduzi-los e agregar valor a produtos sofisticados e 
impostos pelo consumo. Há toda uma manipulação de informações, hoje commodities a serviço da dominação sutil de poucos e poderosos grupos econômicos, que interferem na soberania dos Estados-Nação (DUPAS, 2005).

No campo da decisão há uma grande curiosidade pelo sucesso de algumas corporações japonesas que praticam um tipo de decisão compartilhada, o ringis eido (OUCHI, 1986), muito mais pelo que propicia de lucros crescentes, do que pelo que possa representar em termos de gestão coletiva de negócios. O Brasil, por outro lado, pode apresentar alguns exemplos pouco explorados de possíveis soluções no campo da gestão da informação e do conhecimento, com mais conteúdo social e resultados mais coletivos, desenvolvendo outras práticas gerenciais. Assim é possível estudar como funcionam as redes da economia solidária do Sul, as nossas conhecidas escolas de samba e, acima de tudo, os nossos APLs. O traço comum a essas instituições é a relevância que se dá ao saber popular, à divisão de tarefas, à informação compartilhada e à solidariedade de suas redes sociais.

A ambiguidade do fluxo de informações que sustenta $o$ ambiente informacional de uma empresa opera um conhecimento, que paradoxalmente, pode reduzir o grau de incerteza da decisão e propiciar uma escolha mais eficaz dentre as alternativas avaliadas, especialmente nas inovações. No caso de empresas do APL, esse processo aparentemente concentrado nos gerentes ou proprietários, representa ponto crucial da sobrevivência não só dos seus negócios, mas afeta gerações futuras de suas famílias e o equilíbrio socioeconômico da comunidade.

O caminho natural, dada a amplitude dessas conseqüências, é que esses empresários desencadeiem um amplo processo de construção coletiva das decisões, que começa pelo compartilhamento de informações e conhecimentos que circulam informalmente pela rede sociológica do APL.

Assim, há uma repartição de responsabilidades pela decisão, que envolve proprietários, empregados, familiares e instituições da comunidade. Esses atores propiciam um importante significado: aumentam a segurança e a legitimidade da decisão tomada. Este esforço interativo relatado pelos entrevistados em nossa pesquisa é uma forma estruturada aplicável a outras instituições e empresas, dentro de um modelo mais participativo que fortaleça a organização e construa um processo mais socializado da atividade econômica. E a informação assim compartilhada poderá ser 0 veículo fundamental desta transformação. 


\section{REFERÊNCIAS}

AGUIAR, Afrânio . C. Informação e atividades de desenvolvimento científico, tecnológico e industrial: tipologia proposta com base em análise funcional. Ciência da Informação, Brasília, v.20, n.1, p. 7-15, jan./jun. 1991.

ALBAGLI, Sarita; MACIEL, Maria L. Capital social e desenvolvimento local. In: LASTRES, Helena Maria Martins; CASSIOLATO, José Eduardo; MACIEL; Maria Lúcia (Org.). Pequena empresa: cooperação e desenvolvimento local. Rio de Janeiro: Relume Dumará, 2003.

ALBAGLI, Sarita. Globalização e espacialidade: o novo papel do local. In: . Globalização \& inovação

localizada: experiências de sistemas locais no Mercosul. Brasília: IBICT/MCT, 1999.

ALCARÁ, Adriana Rosecler. et al. As redes sociais como instrumento estratégico para a inteligência competitiva.

Transinformação, Campinas, v.18, n.2, p.143-153, maio/ago. 2006.

ALVARENGA NETO, R.; BARBOSA, R.; CENDON, B. V. A construção da metodologia de pesquisa qualitativa com vistas à apreensão da realidade organizacional brasileira: estudos de casos múltiplos para a proposição de modelagem conceitual integrativa. Informação e Sociedade, v. 16, n. 2, p. 69-86, jul./dez., 2006.

AUSTER, E.; CHOO, Chun Wei. Enviromental Scanning: a conceptual framework for studying the information seeking behvior of executives. In: ANNUAL MEETING OF THE AMERICAN SOCIETY FOR INFORMATION SCIENCE, 54., 1991, Washingthon, DC. Proceedings... Washingthon, DC: Jose Marie Griffiths, Medfort, October, 27-31, 1991.

BARBOSA, Ricardo. R. Acesso e necessidades de informação de profissionais brasileiros: um estudo exploratório. Perspectivas em Ciência da Informação, Belo Horizonte, v. 2. n. 1, 1997.

BAUMAN, Zygmunt. Globalização: as conseqüências humanas. Rio de Janeiro: Jorge Zahar, 1999.

CAPURRO, Rafael. Epistemologia $Y$ ciência de la información. In: ENCONTRO NACIONAL DE PESQUISA EM CIÊNCIA DA INFORMAÇÃO, 5, 2003. Belo Horizonte. Anais... Belo Horizonte: UFMG, 2003.

CARDOSO, Ana Maria. Retomando possibilidades conceituais: uma contribuição à sistematização do campo social. Revista da Escola de Biblioteconomia da UFMG, Belo Horizonte, v. 23, n. 2, p. 107-114, jul./dez. 1994.

CHIAVENATTO, Idalberto. Administração nos novos tempos. Rio de Janeiro:

Campus, 2006.

$\mathrm{CHOO}$, Chun Wei. A Organização do conhecimento: como as organizações usam a informação para criar significado, construir conhecimento e tomar decisões. São Paulo: Senac, 2003.

DAMANPOUR, Faribordz. Bureaucracy and innovation revisited: effects of contingency factors, industrial sectors and innovation characteristics. The Journal of High Technology Mannagement Research, v. 7, n. 2, p. 149-173, 1996.

DANTAS, Marcos. Informação como trabalho e como valor. Revista da Sociedade Brasileira de Economia Política, Rio de Janeiro, n. 19, p. 44-72, 2006.

DAVENPORT, T. H. Ecologia da informação: porque só a tecnologia não basta para o sucesso na era da informação. 3. ed. São Paulo: Futura, 2001. 
DOMINGUES, Ivan. Epistemologia das ciências humanas: o positivismo e a hermenêutica. São Paulo: Loyola, 2004.

DUPAS, Gilberto. Atores e poderes na nova ordem global. São Paulo: UNESP, 2005.

FLANAGAN, John C. The critical incidental technique. American Institute for Research and University of Pittsburgh. Psycological Bulletin, v. 51, n. 4, Jul. 1954.

FREITAS, C. G. Necessidade de informação por parte de gerentes e técnicos: um estudo comparativo. Belo Horizonte, 1996. Dissertação (Mestrado) Escola de Biblioteconomia da Universidade Federal de Minas Gerais, Belo Horizonte, 1996.

GADALETA, Sabino et al. Short-term ambiguity assessment to augment tracking data association information. In: Information Fusion, 2005 7th International Conference on, Fort Collins, California - USA, v. 1, 2005.

GIDDENS, Anthony. A constituição da sociedade. 2. ed. São Paulo: Martins Fontes, 2003.

HUNT, E.K; SHERMAN, Howard J. História do pensamento econômico. 2. ed. Petrópolis: Vozes, 1978.

JENNINGS, David; WATTAN, Stuart. Decision making an integrated approach. London: Pitman Publishing, 1994.

JOHNSON, Allan G. The Blackwell dictionary of sociology. Oxford, England: Blackwell Published, 1995.

KHULTHAU, Carol Collier. The role of the experience in the information search process an earlier career information worker: perception of uncertainty, complexity, construction, an sources. Journal of the American Society for Information Science, v. 50 n. 5, Apr.1999.
LAFORET, Sylvie; TANN, Jennifer. Innovative characteristics of small manufacturing firms. Journal of Small Business and Enterprise Development, v. 13, n. 3, 2006.

LASTRES, Helena M.M.; CASSIOLATO, José Eduardo. Globalização \& inovação localizada: experiências de sistemas locais no Mercosul. Brasília: IBICT/MCT, 1999.

LASTRES, Helena M. M.; CASSIOLATO, J. L.; MACIEL, Maria L. A vez da pequena empresa: uma apresentação. In: Pequena Empresa: Cooperação e desenvolvimento local. Rio de Janeiro: Relume Dumará: UFRJ, Instituto de Economia, 2003.

LEMOS, Cristina. Inovação na Era do conhecimento. In: LASTRES, Helena M.; ALBAGLI, Sarita (Org.). Informação e Globalização na era do conhecimento. Rio de Janeiro: Campus, 1999.

LOPES, Andrés; LUGOÑES, Gustavo. Los sistemas locales en el escenario de la globalización. In: LASTRES, Helena M.M.; CASSIOLATO, José Eduardo.

Globalização \& inovação localizada: experiências de sistemas locais no Mercosul. Brasília: IBICT/MCT, 1999.

LÖWY, Michael. Ideologias e ciência social: elementos para uma análise marxista. 16. ed. São Paulo: Cortez, 2003.

LU, Y. The human in human information acquisition: understanding gatekeeping and proposing new directions in scholarship. Library and Information Science Research, v. 29, n. 1, p. 103-123, Mar. 2007.

MAZZAROL, Tim. Strategic decision making in small innovative firms: the perceived importance of other voices. Disponível em:

$<$ http://64.233.179.104/scholar?hl=ptBR\&Ir=\&q=cache:AVsV4LNgXbgJ:wwwapp iese.edu/eisb/papers/full/paperEISB107.pd $\mathrm{f+Tim+mazzarol+>}$. Acesso em: 08 maio 2008. 
MINTZBERG, Henry; RAISIGHANI, Duru ; THÉORÉT, André. The structure of "unstructured" decision processes. In:

Administrative Science Quarterly, v. 2, n. 21, 1976.

NONAKA, Ikujiro. Knowledge Has to Do with Truth, Goodness, and Beauty.

Entrevista dada a Claus Otto Scharmer.

Tokio, Japan. 23 Fevereiro, 1996.

Disponível em:

$<$ http://www.dialogonleadership.org/Nonak a-1996cp.html>. Acesso em: 08 maio 2007.

NONAKA, Ikujiro; TAKEUCHI, Hirotaka. Criação do conhecimento na empresa: como as empresas japonesas geram a dinâmica da inovação. 11.ed. Rio de Janeiro: Campus, 2003.

; TOYAMA R. The knowledgecreating theory revisited: knowledge creation as a syntesingizing process. Knowledge Management Research \& Pratice, v.1, n.1, p.2-10, 2003. Disponível em: <http://www.palgravejournals.com/kmrp/journal/v1/n1/pdf/85000 01a.pdf>. Acesso em: 15 jan. 2006.

OUCHI, William. Teoria Z: como as empresas podem enfrentar o desafio japonês. 10. ed. São Paulo: Nobel, 1986.

QVORTRUP, Lars. The Controversy over the concept of information: an overview a selected and annotated bibliography. Cybernetic abd Human Knowning, v.1, n.4, 1993.

RAPINI, Márcia; CASSIOLATTO Jose E.; CAMPOS, Renato, BRITO, Jorge. Mensuração e diferenciação de fluxos de conhecimento e informação em APLs brasileiros. Agosto, 2004. Disponível em http://www.sinal.redesist.ie.ufrj.br Acesso em: 3 out. 2007.

RENDÓN ROJAS, Miguel Angel. Relación ente los conceptos: información, concimiento y valor: sejanzas y diferencias. Ciência da Informação, Brasília, v. 34, n. 2, p. 52-61, 2005.
ROBERTS, N., CLARKE, D. Organizational information concepts and information management. International Journal of Information Management, v. 9, n.1, p.2534, March 1989.

SEBRAE. Metodologia de desenvolvimento de arranjos produtivos locais: Projeto Promos - Sebrae - BID: versão 2.0. Brasília: Sebrae, 2004.

SANTOS, Fabiana; CROCCO, Marco; LEMOS, Mauro B. As micro, pequenas e médias empresas em espaços industriais periférico: estudo comparativo entre arranjos produtivos locais de subsistência e centro radial. In: LASTRES, Helena Maria Martins; CASSIOLATO, José Eduardo; MACIEL, Maria Lúcia (Org.). Pequena empresa: cooperação e desenvolvimento local: Rio de Janeiro: Relume Dumará, 2003.

SHERA, Jesse $H$. The sociological relationships of Information Science. Journal of The American Society for Information Science, v. 22, n. 1, p. 76-80, Mar./April 1971.

SHULTZE. U.; STABELL. C. Knowing what do you now? Discourses and contradictions in knowledge management research. Journal of Management Studies 